\section{MINISTÉRIO DA SOLIDARIEDADE E DA SEGURANÇA SOCIAL}

\author{
Portaria n. $^{\circ} 67 / 2012$
}

\section{de 21 de março}

O Despacho Normativo n. ${ }^{\circ} 12 / 98$, de 25 de fevereiro, definiu as normas reguladoras das condições de instalação e funcionamento dos lares para idosos. Contudo, o facto de o âmbito de aplicação deste normativo suscitar algumas questões, leva a que algumas entidades promotoras desta resposta social continuem a aplicar o Guião Técnico para o Lar de Idosos, aprovado por Despacho do Secretário de Estado da Inserção Social em 1996.

Acresce que o Despacho Normativo n. ${ }^{\circ} 30 / 2006$, de 31 de março, ao pretender facilitar a apreciação de projetos de construção e de pedidos de licenciamento de estruturas residenciais que, embora com os mesmos objetivos dos lares para idosos, diferem destes no modelo de estrutura física, gestão, funcionamento e capacidade, não se mostrou capaz do propósito que lhe estava subjacente, forçando a adoção de soluções que não servem, por sistema, como resposta aos pedidos das entidades promotoras.

Neste contexto, é manifesto o desajustamento entre o enquadramento normativo em vigor e a crescente preocupação com a possibilidade de utilização máxima das capacidades instaladas em condições de qualidade e segurança.

Atendendo a que o XIX Governo Constitucional assumiu o objetivo de lançar um amplo modelo de inovação social, o Programa de Emergência Social (PES) veio consignar a necessidade de apostar na proximidade e na maximização das respostas sociais existentes, rentabilizando a capacidade instalada.

Ao reconhecer o valor incomensurável da dignidade da pessoa humana, ao impor uma preocupação com o auxílio aos mais vulneráveis, com uma atenção especial sobre os mais idosos, o PES prevê a alteração e a simplificação da legislação e dos guiões técnicos que enquadram as respostas sociais, designadamente as dirigidas a pessoas idosas, adaptando-a à realidade nacional e a um cenário de contenção orçamental.

Ao ter em atenção as entidades da economia social que atuam numa lógica de proximidade, o PES vem permitir maximizar as potencialidades de intervenção dessas entidades, garantindo mais e melhores respostas que correspondam às necessidades das pessoas e das famílias, nomeadamente através do aumento do número de vagas, sem prejuízo das condições de qualidade e de segurança das pessoas.

Neste contexto, o presente diploma vem uniformizar a legislação existente, integrando as respostas residenciais para pessoas idosas sob uma designação comum, e proceder ao ajustamento desta resposta social às exigências de uma gestão eficaz e eficiente dos recursos e a uma gestão da qualidade e segurança das estruturas físicas, prevendo diversas modalidades de alojamento, designadamente, $\mathrm{o}$ alojamento em tipologias habitacionais e ou em quartos.

Por outro lado, ao estabelecer as condições de funcionamento e instalação das estruturas residenciais para pessoas idosas vem garantir uma prática harmonizada ao nível das regras orientadoras desta resposta social, qualificando os vários modelos de intervenção existentes, independentemente da natureza do suporte jurídico institucional das mesmas.
Foram ouvidas as entidades representativas das instituições, bem como a Associação de Apoio Domiciliário de Lares e Casas de Repouso de Idosos (ALI).

Assim:

Manda o Governo, pelo Ministro da Solidariedade e da Segurança Social, ao abrigo do artigo $5 .^{\circ}$ do Decreto-Lei n. ${ }^{\circ} 64 / 2007$, de 14 de março, com a redação que lhe foi dada pelo Decreto-Lei n. ${ }^{\circ}$ 99/2011, de 28 de setembro, o seguinte:

\section{Artigo $1 .^{\circ}$}

Objeto

1 - A presente portaria define as condições de organização, funcionamento e instalação a que devem obedecer as estruturas residenciais para pessoas idosas.

2 - Considera-se estrutura residencial para pessoas idosas, o estabelecimento para alojamento coletivo, de utilização temporária ou permanente, em que sejam desenvolvidas atividades de apoio social e prestados cuidados de enfermagem.

\section{Artigo 2. ${ }^{\circ}$}

Âmbito de aplicação

1 - As disposições constantes no presente diploma aplicam-se a estruturas residenciais:

a) A implementar em edifícios a construir de raiz ou em edifícios já existentes a adaptar para o efeito;

b) Com processos, em curso, de licenciamento da construção ou da atividade ou de acordo de cooperação a celebrar com o ISS, I. P., à data da entrada em vigor da presente portaria;

c) Com licença de funcionamento ou autorização provisória de funcionamento ou, quando aplicável, acordo de cooperação celebrado com o Instituto da Segurança Social, I. P. (ISS, I. P.).

2 - Às estruturas residenciais referidas na alínea $c$ ) do número anterior, cujo licenciamento ou acordo de cooperação não tenha sido realizado ao abrigo do anexo I do Despacho Normativo n. ${ }^{\circ} 12 / 98$, de 25 de fevereiro, não lhes é aplicável o disposto nos artigos $15 .^{\circ}$ a $18 .^{\circ}$, salvo quando realizem obras que impliquem um alargamento da capacidade superior a $30 \%$.

3 - Às estruturas residenciais referidas no número anterior que realizem obras que impliquem um alargamento da capacidade até $30 \%$, é-lhes aplicável o disposto no anexo II à presente portaria que dela faz parte integrante.

\section{Artigo $3 .^{\circ}$}

\section{Objetivos}

Constituem objetivos da estrutura residencial, designadamente, os seguintes;

a) Proporcionar serviços permanentes e adequados à problemática biopsicossocial das pessoas idosas;

b) Contribuir para a estimulação de um processo de envelhecimento ativo;

c) Criar condições que permitam preservar e incentivar a relação intrafamiliar;

d) Potenciar a integração social. 


\section{Artigo $4 .^{\circ}$}

\section{Princípios de atuação}

A estrutura residencial rege-se pelos seguintes princípios de atuação:

a) Qualidade, eficiência, humanização e respeito pela individualidade;

b) Interdisciplinaridade;

c) Avaliação integral das necessidades do residente;

d) Promoção e manutenção da funcionalidade e da autonomia;

e) Participação e corresponsabilização do residente ou representante legal ou familiares, na elaboração do plano individual de cuidados.

\section{Artigo 5. \\ Destinatários}

1 - A estrutura residencial destina-se à habitação de pessoas com 65 ou mais anos que, por razões familiares, dependência, isolamento, solidão ou insegurança, não podem permanecer na sua residência.

2 - A estrutura residencial pode, também, destinar-se a pessoas adultas de idade inferior a 65 anos, em situações de exceção devidamente justificadas.

3 - A estrutura residencial destina-se, ainda, a proporcionar alojamento em situações pontuais, decorrentes da ausência, impedimento ou necessidade de descanso do cuidador.

\section{Artigo $6{ }^{\circ}$ \\ Capacidade}

1 - A capacidade máxima da estrutura residencial é de 120 residentes, não podendo ser inferior a 4 residentes.

2 - A estrutura residencial organiza-se por unidades funcionais, entendendo-se por unidade funcional o conjunto de áreas funcionais, fisicamente agrupadas e equipadas, para o alojamento dos residentes em ambiente confortável e humanizado e para a prestação dos serviços previstos no artigo $8 .^{\circ}$

3 - A capacidade máxima de cada unidade funcional é de 60 residentes.

4 - Quando a capacidade da estrutura residencial for até 80 residentes, é dispensada a obrigatoriedade de existência de unidades funcionais.

\section{Artigo 7. ${ }^{\circ}$}

\section{Modalidades de alojamento}

A estrutura residencial pode assumir um das seguintes modalidades de alojamento:

a) Tipologias habitacionais, designadamente apartamentos e ou moradias;

b) Quartos;

c) Tipologias habitacionais em conjunto com o alojamento em quartos.

\section{Artigo $8 .^{\circ}$ \\ Serviços}

1 - A estrutura residencial presta um conjunto de atividades e serviços, designadamente:

a) Alimentação adequada às necessidades dos residentes, respeitando as prescrições médicas; b) Cuidados de higiene pessoal;

c) Tratamento de roupa;

d) Higiene dos espaços;

e) Atividades de animação sociocultural, lúdico-recreativas e ocupacionais que visem contribuir para um clima de relacionamento saudável entre os residentes e para a estimulação e manutenção das suas capacidades físicas e psíquicas;

f) Apoio no desempenho das atividades da vida diária;

g) Cuidados de enfermagem, bem como o acesso a cuidados de saúde;

h) Administração de fármacos, quando prescritos.

2 - A estrutura residencial deve permitir:

a) A convivência social, através do relacionamento entre os residentes e destes com os familiares e amigos, com os cuidadores e com a própria comunidade, de acordo com os seus interesses;

b) A participação dos familiares ou representante legal, no apoio ao residente sempre que possível e desde que este apoio contribua para um maior bem-estar e equilíbrio psicoafetivo do residente.

3 - A estrutura residencial pode, ainda, disponibilizar outro tipo de serviços, visando a melhoria da qualidade de vida do residente, nomeadamente, fisioterapia, hidroterapia, cuidados de imagem e transporte.

4 - A estrutura residencial deve ainda permitir a assistência religiosa, sempre que o residente o solicite, ou, na incapacidade deste, a pedido dos seus familiares ou representante legal.

\section{Artigo 9. ${ }^{\circ}$ \\ Processo individual}

1 - É obrigatória a elaboração de um processo individual do residente, com respeito pelo seu projeto de vida, suas potencialidades e competências, do qual constam, designadamente:

a) Identificação do residente;

b) Data de admissão;

c) Identificação do médico assistente;

d) Identificação e contacto do representante legal ou dos familiares;

e) Identificação da situação social;

f) Exemplar do contrato de prestação de serviços;

g) Processo de saúde, que possa ser consultado de forma autónoma;

h) Plano individual de cuidados (PIC), o qual deve conter as atividades a desenvolver, o registo dos serviços prestados e a identificação dos responsáveis pela elaboração, avaliação e revisão do PIC;

i) Registo de períodos de ausência, bem como de ocorrências de situações anómalas;

j) Cessação do contrato de prestação de serviços com indicação da data e motivo.

2 - O processo individual deve estar atualizado e é de acesso restrito nos termos da legislação aplicável.

Artigo $10 .^{\circ}$

Contrato de prestação de serviços

1 - Devem ser celebrados por escrito contratos de alojamento e prestação de serviços com os residentes e 
ou seus familiares e, quando exista, com o representante legal, donde constem os direitos e obrigações das partes.

2 - Do contrato é entregue um exemplar ao residente e ou familiares e arquivado outro no respetivo processo individual.

3 - Qualquer alteração ao contrato é efetuada por mútuo consentimento e assinada pelas partes.

\section{Artigo 11. \\ Direção técnica}

1 - A direção técnica da estrutura residencial é assegurada por um técnico com formação superior em ciências sociais e do comportamento, saúde ou serviços sociais e, preferencialmente, com experiência profissional para o exercício das funções.

2 - Ao diretor técnico compete, em geral, dirigir o estabelecimento, assumindo a responsabilidade pela programação de atividades e a coordenação e supervisão de todo o pessoal, atendendo à necessidade de estabelecer o modelo de gestão técnica adequada ao bom funcionamento do estabelecimento, e em especial:

a) Promover reuniões técnicas com o pessoal;

b) Promover reuniões com os residentes, nomeadamente para a preparação das atividades a desenvolver;

c) Sensibilizar o pessoal face à problemática da pessoa idosa;

d) Planificar e coordenar as atividades sociais, culturais e ocupacionais dos idosos.

3 - As funções do diretor técnico podem ser exercidas a $50 \%$, quando a capacidade da estrutura residencial for inferior a 30 residentes.

4 - Quando a capacidade da estrutura residencial for inferior a 15 residentes, o diretor técnico poderá ter um horário semanal variável, mas deve assegurar, no mínimo, uma permanência diária de três horas no estabelecimento.

\section{Artigo $12 .^{\circ}$}

\section{Pessoal}

1 - A estrutura residencial deve dispor de pessoal que assegure a prestação dos serviços 24 horas por dia.

2 - A estrutura residencial, para além do diretor técnico, deve dispor no mínimo de:

a) Um(a) animador(a) sociocultural ou educador(a) social ou técnico de geriatria, a tempo parcial por cada 40 residentes;

b) Um(a) enfermeiro(a), por cada 40 residentes;

c) Um(a) ajudante de ação direta, por cada 8 residentes;

d) Um(a) ajudante de ação direta por cada 20 residentes, com vista ao reforço no período noturno;

e) Um(a) encarregado(a) de serviços domésticos em estabelecimentos com capacidade igual ou superior a 40 residentes;

f) Um(a) cozinheiro(a) por estabelecimento;

g) Um(a) ajudante de cozinheiro(a) por cada 20 residentes;

h) Um(a) empregado(a) auxiliar por cada 20 residentes.

3 - Sempre que a estrutura residencial acolha idosos em situação de grande dependência, os rácios de pessoal de enfermagem, ajudante de ação direta e auxiliar são os seguintes:

a) Um(a) enfermeiro(a), para cada 20 residentes;

b) Um(a) ajudante de ação direta, por cada 5 residentes;

c) Um(a) empregado(a) auxiliar por cada 15 residentes.

4 - Os indicadores referidos nos números anteriores podem ser adaptados, com a necessária flexibilidade, em função das características gerais, quer de instalação, quer de funcionamento, quer do número de residentes de cada estrutura residencial.

5 - Nos casos em que os serviços de higiene do ambiente, de tratamento de roupa e de confeção de refeições sejam objeto de contratualização externa pode dispensar-se o pessoal de cozinha e de limpeza.

6 - A estrutura residencial pode contar com a colaboração de voluntários, devidamente enquadrados, não podendo estes ser considerados para efeitos do disposto nos números anteriores.

\section{Artigo $13 .^{\circ}$}

\section{Acesso à informação}

A estrutura residencial deve proceder à afixação, em local visível e de fácil acesso, designadamente, dos seguintes elementos:

a) Licença de funcionamento ou autorização provisória de funcionamento, quando aplicável;

b) Identificação da direção técnica;

c) Horários de funcionamento das atividades e serviços;

d) Mapa semanal das ementas, incluindo dietas;

e) Preçário e ou tabela da comparticipação familiar;

f) Publicitação dos apoios financeiros da segurança social, quando aplicável;

g) Referência à existência de livro de reclamações.

\section{Artigo $14 .^{\circ}$}

\section{Regulamento interno}

1 - A estrutura residencial possui obrigatoriamente regulamento interno, o qual define as regras e os princípios específicos de funcionamento e contém, designadamente:

a) Condições, critérios e procedimentos de admissão;

b) Direitos e deveres da estrutura residencial e do residente ou representante legal ou familiares;

c) Horário das visitas;

d) Critérios de determinação das comparticipações familiares, quando aplicável.

2 - Um exemplar do regulamento interno é entregue ao residente, familiar ou representante legal no ato de celebração do contrato de prestação de serviços.

3 - Qualquer alteração ao regulamento interno deve ser comunicada ao ISS, I. P.

\section{Artigo $15 .^{\circ}$}

\section{Condições de implantação}

1 - A estrutura residencial deve estar inserida na comunidade, preferencialmente em local servido por transportes públicos e ter acesso fácil a pessoas e viaturas. 
2 - Na implantação da estrutura residencial deve ter-se em conta:

a) A proximidade a outros estabelecimentos de apoio social, de saúde e de âmbito recreativo e cultural;

b) A coesão do edifício na malha e envolvente urbana, por forma a favorecer a integração, a comunicabilidade e as relações de proximidade e vizinhança;

c) A proximidade a parques urbanos, jardins públicos e outros espaços naturais suscetíveis de proporcionar passeio e convivência social.

3 - O edifício deve ser implantado em zona de boa salubridade e longe de estruturas ou infraestruturas que provoquem ruído, vibrações, cheiros, fumos e outros poluentes, considerados perigosos para a saúde pública e que perturbem ou possam interferir no normal quotidiano dos residentes.

\section{Artigo $16^{\circ}$ \\ Edifício}

1 - A estrutura residencial deve funcionar, preferencialmente, em edifício autónomo ou num conjunto edificado autónomo.

2 - A conceção do edifício ou do conjunto de edifícios deve obedecer a parâmetros espaciais, designadamente de âmbito físico e cognitivo, conducentes ao bem-estar dos residentes, à facilidade no desenvolvimento das tarefas dos prestadores de serviços e, ainda:

a) Permitir a maleabilidade com vista a adaptações espaciais ou a melhorias tecnológicas, pela introdução de materiais e equipamentos adequados às respetivas necessidades;

b) Introduzir sistemas construtivos que permitam a fácil manutenção do edifício;

c) Valorizar a eficácia na gestão energética e ambiental, promovendo a sustentabilidade do sistema construído e a do meio ambiente;

\section{Artigo 17.}

\section{Acessos ao edifício}

1 - O edifício deve ter acessos facilitados através da via pública, quer viários quer pedonais, devidamente identificados e legíveis.

2 - O edifício deve prever lugares de estacionamento de viaturas, em número adequado à capacidade da estrutura residencial, de acordo com os regulamentos camarários em vigor.

3 - Na omissão de regulamentos camarários é obrigatório prever-se no mínimo um lugar que sirva ambulâncias, cargas e descargas.

4 - No edifício onde está instalada a estrutura residencial é obrigatório prever-se:

a) Acesso principal para os residentes, colaboradores e visitantes;

b) Acesso de serviço destinado às áreas de serviços e ao acesso de viaturas para cargas e descargas e recolha de lixo.

\section{Artigo $18 .^{\circ}$}

\section{Áreas funcionais}

1 - A estrutura residencial é composta pelas seguintes áreas funcionais:

a) Receção;

b) Direção, serviços técnicos e administrativos; c) Instalações para o pessoal;

d) Convívio e atividades;

e) Refeições;

f) Alojamento;

g) Cozinha e lavandaria;

h) Serviços de enfermagem;

i) Serviços de apoio.

2 - Quando exista mais do que uma unidade funcional, cada unidade é autónoma no que se refere às áreas funcionais referidas nas alíneas $d$ ) e $f$ ) do número anterior.

3 - As áreas funcionais devem obedecer a um conjunto de requisitos específicos que constam do anexo I à presente portaria, que dela faz parte integrante.

4 - Em casos devidamente justificados e autorizados podem as áreas funcionais constantes do anexo I ter alterações face às áreas úteis mínimas nele previstas.

\section{Artigo $19 .^{\circ}$}

\section{Avaliação e fiscalização}

1 - O funcionamento da estrutura residencial está sujeito a acompanhamento, avaliação e fiscalização por parte dos serviços competentes do Instituto da Segurança Social, I. P. (ISS).

2 - Para efeitos do disposto no número anterior, a entidade responsável pela estrutura residencial deve facultar o acesso às instalações e à documentação tida por conveniente.

\section{Artigo $20 .^{\circ}$}

\section{Casos especiais}

Para as estruturas residenciais referidas na alínea $c$ ) do artigo $2 .^{\circ}$ que realizem obras indispensáveis ao reforço da segurança e ao melhoramento das condições de vida dos residentes e à qualidade da prestação dos serviços é dispensado o parecer do ISS, referido no $\mathrm{n}^{\circ} 2$ do artigo $7 .^{\circ}$ do Decreto-Lei n. ${ }^{\circ}$ 64/2007, de 14 de março, na redação que lhe foi dada pelo Decreto-Lei n. ${ }^{\circ}$ 99/2011, de 28 de setembro, salvo quando tais obras impliquem um aumento da capacidade.

\section{Artigo 21. \\ Revogação}

São revogados o Despacho Normativo n. ${ }^{\circ}$ 12/98, de 25 de fevereiro, o Despacho Normativo n. ${ }^{\circ} 30 / 2006$, de 31 de março, e o Despacho Normativo n. ${ }^{\circ} 3 / 2011$, de 16 de fevereiro.

$$
\text { Artigo 22. }{ }^{\circ}
$$

Entrada em vigor

A presente portaria entra em vigor no dia seguinte ao da sua publicação.

O Ministro da Solidariedade e da Segurança Social, Luís Pedro Russo da Mota Soares, em 12 de março de 2012.

ANEXO I

\section{Áreas funcionais}

Ficha 1 - Área de receção

1.1 - Destina-se à receção, ao atendimento e espera. 1.2 - A iluminação deve ser adequada para espaço de transição com o exterior, protegida das intempéries e 
permitir o fácil encaminhamento para os acessos verticais e horizontais do edifício.

1.3 - A área a considerar depende diretamente da dimensão da estrutura residencial: área útil mínima: $9 \mathrm{~m}^{2}$.

1.4 - Na proximidade desta área devem prever-se instalações sanitárias, separadas por sexo, e acessíveis a pessoas com mobilidade condicionada.

\section{Ficha 2 - Área de direção, serviços técnicos e administrativos}

2.1 - Destina-se a local de trabalho da direção do estabelecimento e do pessoal técnico e administrativo, arquivo administrativo e expedientes vários.

2.2 - Deve localizar-se na proximidade da receção e incluir os seguintes espaços com as áreas úteis mínimas de:

a) Gabinete da direção: $10 \mathrm{~m}^{2}$;

b) Gabinete(s) técnico(s): $2 \mathrm{~m}^{2} /$ posto trabalho; área útil mínima: $10 \mathrm{~m}^{2}$;

c) Gabinete(s) administrativo(s): $2 \mathrm{~m}^{2} /$ posto trabalho; área útil mínima: $10 \mathrm{~m}^{2}$;

d) Sala de reuniões, quando a capacidade for igual ou superior a 40 residentes: $10 \mathrm{~m}^{2}$;

e) Instalação sanitária, que pode ser dispensada se houver outra na proximidade: $3 \mathrm{~m}^{2}$.

2.3 - O gabinete administrativo poder ser dispensado desde que fiquem asseguradas as funções administrativas.

\section{Ficha 3 - Área de instalações para o pessoal}

3.1 - Destina-se ao pessoal, e será localizada onde melhor se considerar, desde que se assegure o fácil acesso aos funcionários e não implique atravessamentos de circulações com outras áreas funcionais distintas.

3.2 - Deve incluir os seguintes espaços com as áreas úteis mínimas de:

a) Sala de pessoal: $10 \mathrm{~m}^{2}$;

b) Instalação sanitária, com equipamento sanitário completo, incluindo base de duche, sempre que não existam as instalações sanitárias previstas no número seguinte: $3,5 \mathrm{~m}^{2}$.

3.3 - Devem ser incluídas instalações para o pessoal em funções na cozinha e lavandaria sempre que a estrutura residencial tenha uma capacidade superior a 15 residentes, com os seguintes espaços e com a área útil mínima de:

a) Vestiário, zona de descanso: $6 \mathrm{~m}^{2}$;

b) Instalação sanitária: $3,5 \mathrm{~m}^{2}$.

\section{Ficha 4 - Área de convívio e atividades}

4.1 - Destina-se a convívio, lazer e atividades a desenvolver pelos residentes e deve localizar-se na proximidade da receção ou ter uma articulação fácil com esta.

4.2 - Para atividades específicas, deve esta área estar apta ao uso de utensílios de trabalho, conforme o caso, bem como ter as condições ambientais e de iluminação e de conforto necessárias.

4.3 - Deve incluir os seguintes espaços com as áreas úteis mínimas de:

a) Salas de estar/atividades: $2 \mathrm{~m}^{2} /$ residente, para uma utilização, em simultâneo, no mínimo de $80 \%$ dos residentes; área útil mínima: $15 \mathrm{~m}^{2}$;

b) Instalações sanitárias separadas por sexo, em que o equipamento a instalar será em número adequado, consi- derando uma cabine com sanita por cada 10 residentes e um lavatório por cada 10 residentes e, pelo menos uma delas, acessível a pessoas com mobilidade condicionada $\operatorname{com} 4,84 \mathrm{~m}^{2}$.

4.4 - As instalações sanitárias podem ser dispensadas desde que haja proximidade entre a sala de convívio e atividades e as instalações sanitárias previstas para a área de refeições.

4.5 - Em edifícios a adaptar, a sala de convívio e atividades pode ser comum à sala de refeições: área útil mínima: $30 \mathrm{~m}^{2}$.

\section{Ficha 5 - Área de refeições}

5.1 - Destina-se à tomada de refeições.

5.2 - Esta área deve incluir os seguintes espaços com as áreas úteis mínimas:

a) Sala de refeições: $2 \mathrm{~m}^{2} /$ residente, para uma utilização, em simultâneo, no mínimo de 80 \% dos residentes; área útil mínima: $20 \mathrm{~m}^{2}$. Podem ser projetadas zonas de refeição, sendo a área total necessária deste compartimento subdividida em pequenos espaços por qualquer tipo de paramento amovível ou equipamento móvel;

b) Instalações sanitárias separadas por sexo, em que o equipamento a instalar será de lavatório e sanita em número adequado, considerando uma cabine com sanita por cada 10 residentes e um lavatório por cada 10 residentes e, pelo menos uma delas, acessível a pessoas com mobilidade condicionada com $4,84 \mathrm{~m}^{2}$.

5.3 - A sala de refeições não pode ser local de passagem para outras áreas funcionais e deve ter boas condições acústicas e ligação visual com o exterior.

5.4 - As instalações sanitárias podem ser dispensadas desde que haja proximidade entre a sala de refeições e as instalações sanitárias previstas para a área de convívio e atividades.

5.5 - Em edifícios a adaptar a sala de refeições pode ser comum à sala de convívio e atividades: área útil mínima: $30 \mathrm{~m}^{2}$.

\section{Ficha 6 - Área de alojamento}

6.1 - Destina-se a descanso dos residentes e deve localizar-se em zona de acesso restrito.

6.2 - Na modalidade de alojamento em tipologia habitacional:

6.2.1 - Os apartamentos e ou moradias devem apresentar os seguintes espaços, com as áreas úteis mínimas:

a) Quartos individuais ou duplos: $10 \mathrm{~m}^{2}$ e $16 \mathrm{~m}^{2}$, respetivamente;

b) Sala/zona de estar com copa/kitchenet: $10 \mathrm{~m}^{2}$;

c) Instalação sanitária, com duche embutido ou nivelado com o pavimento: $4,5 \mathrm{~m}^{2}$;

d) Zona de arrumos.

6.2.2 - A capacidade de cada apartamento/moradia é no máximo de quatro residentes, sendo a capacidade máxima por quarto de dois residentes.

6.3 - Na modalidade de alojamento em quartos, estes devem estar agrupados de acordo com a estrutura do edifício, por forma a permitir um ambiente mais humanizado. 
6.3.1 - Os espaços a considerar com as áreas úteis mínimas, são:

a) Quarto individual: $10 \mathrm{~m}^{2}$. Pode ser utilizado como quarto de casal, devendo para esse efeito ter uma área útil mínima de $12 \mathrm{~m}^{2}$;

b) Quarto duplo: $16 \mathrm{~m}^{2}$;

c) Quarto triplo: 20,5 $\mathrm{m}^{2}$;

d) Instalações sanitárias próprias, podendo servir, no máximo, quatro residentes, sendo de acesso privado ou localizando-se na proximidade dos quartos: $4,5 \mathrm{~m}^{2}$;

e) Sala de estar com copa, por cada agrupamento de quartos: $12 \mathrm{~m}^{2}$.

6.3.2 - Deve existir um compartimento de sujos por cada piso da área de alojamento.

6.3.3 - Os quartos podem ser individuais, duplos ou triplos, sendo que, pelo menos, $20 \%$ devem corresponder a quartos individuais e, no máximo, $20 \%$ a quartos triplos.

6.3.4 - Deve prever-se entre camas um sistema amovível que garanta a privacidade dos residentes. As camas devem ser, preferencialmente, articuladas, tendo em conta situações de residentes com elevado grau de dependência.

6.4 - Deve existir banho geriátrico com a área útil mínima de $10 \mathrm{~m}^{2}$ quando a capacidade da estrutura residencial for superior a 20 residentes.

6.5 - A sala de estar com copa pode ser dispensada em unidades funcionais com capacidade não superior a 20 residentes.

6.6 - Na modalidade de alojamento em tipologias habitacionais em simultâneo com alojamento em quartos, os espaços a considerar são os referidos nos números anteriores, consoante o caso.

\section{Ficha 7 - Área de cozinha e lavandaria}

7.1 - Destina-se à preparação de refeições e ao tratamento de roupa.

7.2 - A cozinha deve ser dimensionada ao número de refeições a confecionar ou servir e ser objeto de projeto específico para a instalação dos equipamentos de trabalho fixos e móveis, bem como dos aparelhos e máquinas necessários, sempre que a capacidade seja superior a 15 residentes.

7.2.1 - Os espaços a considerar são:

a) Um espaço principal, organizado em três zonas: zona de higienização dos manipuladores de alimentos; zona de preparação de alimentos e zona de confeção de alimentos;

b) Espaço complementar, integrado no espaço principal ou com comunicação direta com este, organizado em duas outras zonas: zona de lavagem de loiça e de utensílios de cozinha (também designada por copa suja) e zona de distribuição das refeições (também designada por copa limpa);

c) Espaços anexos, compostos por despensa, compartimento de frio e compartimento do lixo.

7.2.2 - A área mínima útil da cozinha é de $10 \mathrm{~m}^{2}$.

7.2.3 - Caso a estrutura residencial recorra à confeção de alimentos no exterior, a cozinha pode ser simplificada, devendo existir os espaços necessários para proceder, em condições de higiene e de bom funcionamento, à receção e armazenamento das refeições e ao seu aquecimento e respetiva distribuição.

7.3 - A lavandaria deve localizar-se junto ao acesso de serviços e deve ser dimensionada ao número de residentes.

7.3.1 - Os espaços a considerar devem ter em conta:

a) Depósito para receção da roupa suja;

b) Máquinas de lavar e secar roupa;

c) Depósito, armários e prateleiras para guardar a roupa lavada;

d) Mesa de costura e bancada para passar a roupa a ferro.

7.3.2 - A área mínima útil da lavandaria é de $12 \mathrm{~m}^{2}$.

7.3.3 - Caso a estrutura residencial recorra ao tratamento da roupa no exterior, a lavandaria pode ser simplificada, devendo existir os espaços necessários para proceder, em condições de higiene e de bom funcionamento, ao envio e à receção da roupa e respetivo depósito e separação.

\section{Ficha 8 - Área de serviços de enfermagem}

8.1 - Destina-se à prestação de cuidados de enfermagem aos residentes, sendo, sempre que necessário, ocupada por médico assistente para atendimento dos residentes.

8.2 - Esta área deve incluir:

a) Gabinete de enfermagem, com lavatório e marquesa, com a área útil mínima de $12 \mathrm{~m}^{2}$;

b) Instalação sanitária anexa ao gabinete de enfermagem: $3,5 \mathrm{~m}^{2}$, caso não exista outra na proximidade.

\section{Ficha 9 - Área de serviços de apoio}

9.1 - Destina-se à arrumação e armazenagem de equipamento, mobiliário, materiais e produtos necessários ao funcionamento da estrutura residencial.

9.2 - Esta área deve incluir os seguintes espaços:

a) Arrecadações gerais;

b) Arrecadações de géneros alimentícios;

c) Arrecadações de equipamentos e produtos de higiene do ambiente.

\section{ANEXO II}

\section{Estruturas residenciais a que se refere o n. ${ }^{\circ} 2$ do artigo $2 .^{\circ}$}

1 - A área dos quartos individuais não pode ser inferior a $9 \mathrm{~m}^{2}$.

2 - Nos quartos duplos e triplos, a área mínima admitida por cama é de $6 \mathrm{~m}^{2}$, exceto no caso de camas articuladas, em que deve ser de $7 \mathrm{~m}^{2}$, recomendando-se, em qualquer dos casos, que a distância entre as camas não seja inferior a $0,9 \mathrm{~m}$.

3 - Nas salas de convívio e atividades, a área mínima admitida por residente é de $1,20 \mathrm{~m}^{2}$, não podendo a sala ter uma área inferior a $12 \mathrm{~m}^{2}$.

4 - Na sala de refeições, a área mínima admitida por residente é de $1,20 \mathrm{~m}^{2}$, não podendo a sala ter uma área inferior a $12 \mathrm{~m}^{2}$.

5 - No caso de existir apenas uma sala (atividades/refeições), a área mínima admitida é de $2,20 \mathrm{~m}^{2} /$ residente, não podendo a sala ter uma área inferior a $16 \mathrm{~m}^{2}$.

6 - Nas instalações sanitárias deve considerar-se uma sanita e um lavatório por cada 10 residentes, devendo pelo menos uma delas ser acessível a pessoas com mobilidade condicionada com $4,84 \mathrm{~m}^{2}$.

7 - O gabinete de enfermagem, com lavatório, deve ter uma área mínima de $10 \mathrm{~m}^{2}$. 